\title{
Effect of Contact Time Between Silicone Impression Materials and Stone on Dimensional Stability of Resultant Cast
}

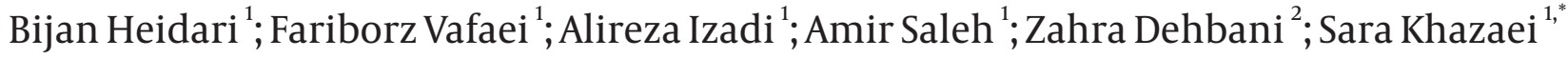 \\ ${ }_{1}^{1}$ Department of Prosthodontics, School of Dentistry, Hamadan University of Medical Sciences, Hamadan, IR Iran \\ ${ }^{2}$ Private Dentistry, Hamadan, IR Iran \\ ${ }^{*}$ Corresponding author: Sara Khazaei, Department of Prosthodontics, School of Dentistry, Hamadan University of Medical Sciences, Hamadan, IR Iran. Tel: +98-9187048221, Fax: + 98- \\ 8138354220, E-mail: sarakhazaei_83@yahoo.com \\ Received: January 10, 2013; Accepted: March 24, 2013
}

\begin{abstract}
Background: Numerous factors have an effect on the accuracy of an impression and resultant cast, and these include: impression material, impression technique, tray selection, impression disinfection, storage time of impression before pouring, stone type used for fabrication of cast. Up to now, there has been little research conducted on the effect of contact time of a cast with an impression, on the dimensional stability of a cast.

Objectives: The purpose of this study was to evaluate the effect of the contact time of silicone impression materials with stone casts, on the dimensional stability of resultant casts.

Materials and Methods: A total of 44 impressions were made from a stainless steel master model, with each one of two silicone impression materials (Elite HD+ and Speedex), and poured with Elite Master Type IV. The thickness of the light-body material ( $1 \mathrm{~mm}$ ) was provided by using four copings. The resulting casts from each material were placed in four groups $(\mathrm{n}=11)$ after each contact time with the impression (1 hour, 24 hours, 48 hours, 1 week). Distance between anterior and posterior abutments was measured for the casts and master model. Data were analyzed by two-way analysis of variance and a Tukey test.

Results: The relationship between the dimensional stability of the casts and the simultaneous effect of the impression material and contact time of the cast with the impression was not statistically significant $(\mathrm{P}=0.099)$. Type of impression material on the dimensional stability of the cast had no significant effect $(\mathrm{P}=0.163)$. Increased contact time of the cast with the impression resulted in increased dimensional change $(\mathrm{P}<0.001)$.

Conclusions: Dimensional stability of the casts after different contact time with the impression was acceptable. The best time to separate the cast from the impression was one hour after pouring the impression.
\end{abstract}

Keywords:President, Silicone Impression Material; Calcium Sulfate; Dental Cast

\section{Background}

Impression making is an important stage for creating dental prosthesis. To produce a precise restoration of the teeth, the cast that the restoration is made from, should be reproduced as accurately as possible from the teeth and surrounding tissues and then poured with the appropriate material (1). Inaccuracy in making the impression and the subsequent cast will have undesirable effects on the restoration of the prepared tooth and require repetition of the impression, waste of time, and extra expenses (2). Many previous studies have been carried out to identify the most effective factors on dimensional accuracy of impressions and resultant casts, so that the most appropriate material and technique can be used in every situation. According to these researches, factors such as: type of tray, impression material, and impression technique, have an effect on the quality of the impression (3-5). In addition, the type of material used for making the cast and the proper pouring time for each impression material, can have an effect on the accuracy of the dental cast $(5,6)$. In order to make dental prosthesis, several impression materials are used, such as: hydrocolloid and elastomeric impression materials (polysulfide, condensation silicone, polyether, and additional silicone) (7). Among all these materials, additional silicones have the most dimensional stability and due to their convenience, their use is increasing (5). Furthermore, condensation silicones are commonly used in Iran (4). The silicone impression material can be hydrophilic or hydrophobic and as a result of these characteristics, increasing the contact time between the cast and the impression can have an effect on the dimensional stability of the casts. Several studies have been done in this field. In a study by Marquezan et al. increasing the contact time between the alginate mold and the cast did not have any effect on the dimensional stability of the cast (8).

\section{Objectives}

Up until the present time, no previous study has been conducted on the effect of the separation time of the cast from the impression, on the dimensional stability of the 
casts obtained from silicone impression materials. Therefore, due to a lack of data, this research aimed to investigate the effect of different contact times between the cast and the impression on the dimensional stability of the resultant cast.

\section{Materials and Methods}

In this experimental-laboratory study using the pattern of Schleier's study (9), one master laboratory model was made. This model consisted of a metal sheet with a dental arch form, which included four abutments and two guiding grooves ( $4 \mathrm{~mm}$ length and $1 \mathrm{~mm}$ depth) on the sides of the abutments (Figure 1). A rim lock tray was used for the impression. For this purpose, cold cure acrylic resin was placed on the two outer edges of the tray and the tray was put on the master model in such a way that the acrylic resin entered the guiding grooves. After polymerization of the acrylic, the tray was taken out of the model and then the tray was ready for the impression (Figure 2).

Dimensions of the abutments and the distances between them are shown below:(Figure 1 )

-The diameter of the abutments: $11 \mathrm{~mm}$

- The height of the abutments: $9.85 \mathrm{~mm}$

-The distance of the anterior and posterior abutments: $28.40 \mathrm{~mm}$

The abutments according to the model in Schleier's study had a $6^{\circ}$ taper relative to the vertical axis and two intersecting grooves were created on their occlusal surfaces. The point at which they intersected was intended as a reference point for the measurement of the distance between the abutments (9). Impression making was carried out with additional silicone (Elite HD+) (Zhermack, Italy) and condensation silicone (Speedex, Coltene, Switzerland). To create a $1 \mathrm{~mm}$ space for the light body material, one stainless steel coping $1 \mathrm{~mm}$ thick was constructed over every abutment using computer design and a computer milling device from the original model (6).

The following method was used for making the impression with putty material (heavy body silicone). First, spacers were placed on the abutments. Then, according to the manufacturer's instructions, putty was prepared and put in the tray. The tray was conformed to the model so that no space was maintained between the tray edges and the guiding grooves. Then, the spacers were removed from the abutments and light body silicone was prepared according to the manufacturer's instructions and put in the tray, before the impression was made. After placing the tray on the model, 3 sinkers with a weight of $0.5 \mathrm{~kg}$ (1.5 kg in total) were placed on it, because the tray needed to be kept firmly in place for the duration of setting the materials (10). The given times in this study are based on research conducted in oral cavities and their findings, because the temperature in laboratory situations is much lower than in the oral cavity. In these researches, the setting time of impression materials is increased and considered twice. Forty-four impressions were taken from the model by each silicone material as mentioned above (Figures 3, 4).

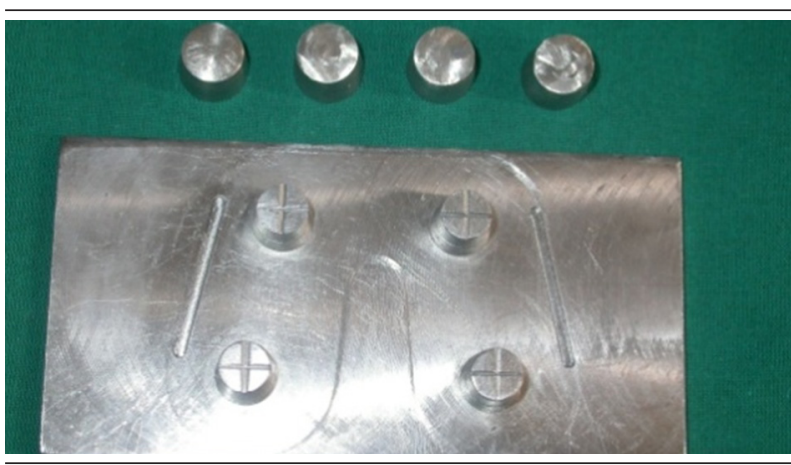

Figure 1. Master Model

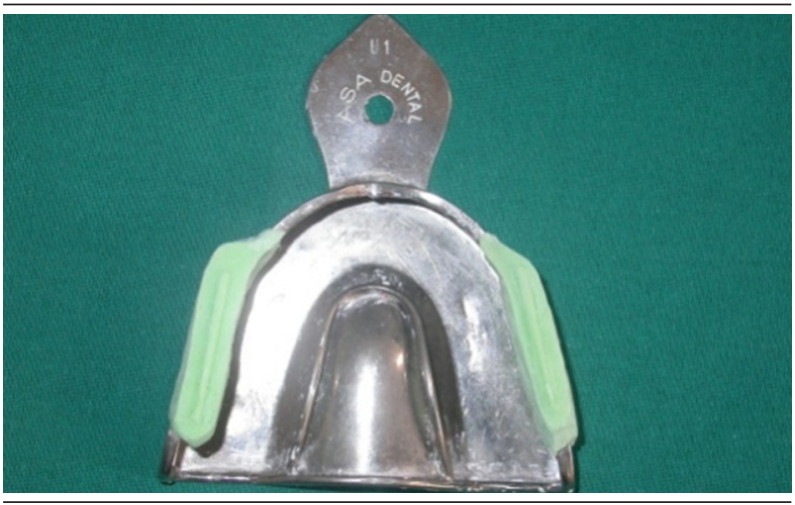

Figure 2. Modified Tray

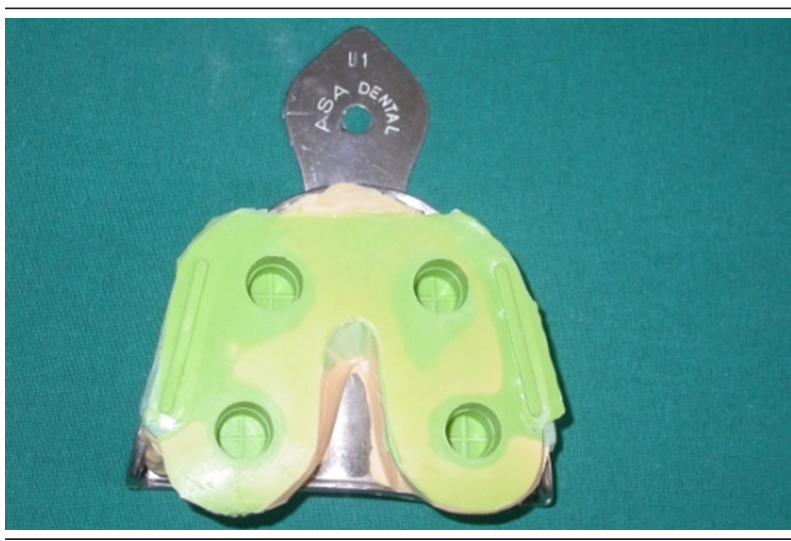

Figure 3. Impression With Elite HD+

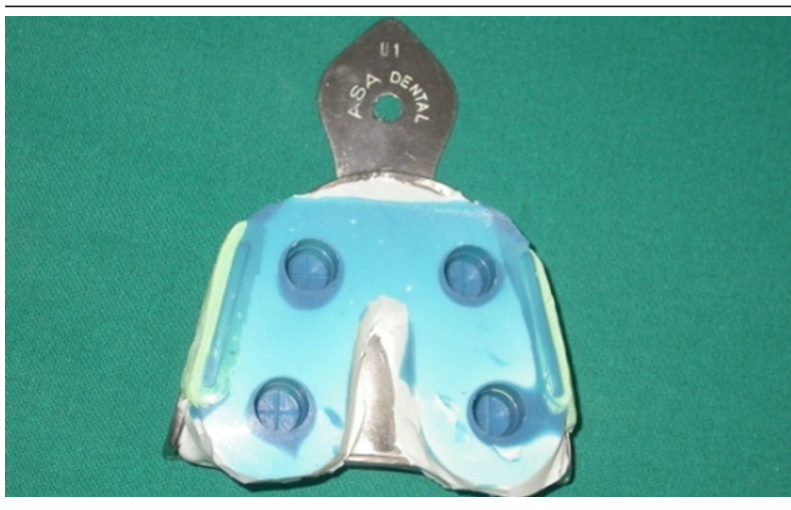

Figure 4. Impression With Speedex 
According to the instructions of the Coltene manufacturer, it is better for Speedex impressions to be poured at least 30 minutes after the impression, therefore, in order to unify all the conditions for both impression materials, all of the impressions were poured after 30 minutes. Type IV Elite Master (Zhermack, Italy) were used for pouring the impressions. The water and powder for the plaster were mixed together according to the manufacturer's instructions and then poured into the impression under vibration. According to the manufacturer's instructions, the setting time of this plaster is 1 hour, therefore: one quarter of the samples (casts) were separated from the impression one hour after pouring, one quarter of the casts after 24 hours, one quarter after 48 hours, and the remaining one-quarter were separated 7 days after pouring the impressions. Therefore, the 8 groups $(n=11)$ in this study included:

1. The casts separated from Elite HD+ impression material after 1 hour

2. The casts separated from Elite HD + impression material after 24 hours

3. The casts separated from Elite HD + impression material after 48 hours

4. The casts separated from Elite HD + impression material after 1 week

5. The casts separated from Speedex impression material after 1 hour

6 . The casts separated from Speedex impression material after 24 hours

7. The casts separated from Speedex impression material after 48 hours

8 . The casts separated from Speedex impression material after 1 week

In order to omit the effect of different factors on the study, a random sequence for conducting the impressions was also considered. After separation of the casts from the impressions, the samples were numbered. Then, the researcher measured the considered dimension (without trimming the casts). The distance between the center of the anterior and posterior abutments on each sample was measured by a digital caliper with 0.01 $\mathrm{mm}$ accuracy, then the value was deducted from this distance $(28.40 \mathrm{~mm})$ on the master model. The number was registered in a check list as the dimensional change of the sample. Positive values indicated expansion and negative values represented contraction of the sample. In this study, the distance between the anterior and posterior abutments was measured. To obtain accurate measurements, the distances were measured three times on each plaster sample and their average was considered as the final result. After measurement, the information was compared to the main model. The variance analysis (twoway ANOVA) compared the effects of the type of material and contact time on dimensional changes of the casts; in addition, a tukey test was used to compare values between each two contact time.

\section{Results}

In this study, the effect of the two types of impression materials (Speedex, Elite HD+) and 4 contact times between the impression and stone on the dimensional stability of the resultant casts was analyzed. The mean values and standard deviation of dimensional changes in the casts after spending 4 different times of contact with two impression materials: Elite $\mathrm{HD}+$ and Speedex are shown in Table 1. The results show that the dimensions of the samples increased and the casts expanded.

The two-way analysis of variance showed that only the effect of the independent variable of contact time on the dimensional stability of the casts was significant, but the type of impression material did not have any significant effect. Also, the interaction between these two variables on the dimensional stability of the casts was not significant $($ Pvalue $=0.099)($ Table 2$)$.

In order to examine the influence of time on the dimensional changes of the casts and to compare the pairs of time together, a tukey test was used. The results concerning the distance between the anterior and posterior abutments showed that the difference of dimensional changes between the times of 1 hour and 24 hours $(\mathrm{P}<$ $0.001), 1$ hour and 48 hours $(\mathrm{P}<0.001), 1$ hour and 1 week $(\mathrm{P}=0.005), 24$ hours, and 1 week $(\mathrm{P}=0.011)$, were significant (Table 3).

Table 1. Mean Values and Standard Deviation of Dimensional Changes of Casts After Four Contact Times With Elite HD+ and Speedex

\begin{tabular}{|c|c|c|c|c|}
\hline $\begin{array}{l}\text { Evaluated param- } \\
\text { eters }\end{array}$ & 1 Hour & 24 Hours & 48 Hours & 1 Week \\
\hline $\begin{array}{l}\text { Dimensional } \\
\text { changes in contact } \\
\text { with Elite HD+ }\end{array}$ & $\begin{array}{l}0.0394 \pm \\
0.02637\end{array}$ & $\begin{array}{l}0.1215 \pm \\
0.02705\end{array}$ & $\begin{array}{l}0.1109 \pm \\
0.04609\end{array}$ & $\begin{array}{l}0.0221 \pm \\
0.01360\end{array}$ \\
\hline $\begin{array}{l}\text { Dimensional } \\
\text { changes in contact } \\
\text { with Speedex }\end{array}$ & $\begin{array}{l}0.0730 \pm \\
0.02648\end{array}$ & $\begin{array}{l}0.1255 \pm \\
0.03426\end{array}$ & $\begin{array}{l}0.0952 \pm \\
0.02998\end{array}$ & $\begin{array}{l}0.1006 \pm \\
0.03269\end{array}$ \\
\hline
\end{tabular}

Table 2. Effect of Independent Variables of Type of

Material,Time of Contact and Their Interaction on Measured Dimensions (Two-way ANOVA)

\begin{tabular}{lc}
\hline Variables & P value \\
\hline Type of material & 0.163 \\
Time of contact & $<0.001^{\mathrm{a}}$ \\
Type of material and contact time & 0.099 \\
\hline${ }^{\mathrm{a}}$ Statistically significant. &
\end{tabular}

Table 3. P values in Pairs, Comparison of Times and Distance Between Anterior and Posterior Abutments

\begin{tabular}{lc}
\hline Compared Times & P value \\
\hline $\mathbf{1}$ hour-24 hours & $<0.001^{\mathrm{a}}$ \\
$\mathbf{1}$ hour-48 hours & $<0.001^{\mathrm{a}}$ \\
$\mathbf{1}$ hour-1 week & $0.005^{\mathrm{a}}$ \\
$\mathbf{2 4}$ hours-48 hours & 0.189 \\
$\mathbf{2 4}$ hours-1 week & $0.011^{\mathrm{a}}$ \\
$\mathbf{4 8}$ hours-1 week & 0.658 \\
\hline
\end{tabular}

a Tukey test. 


\section{Discussion}

In order to make each prosthesis with good adaptation, it is important to have an accurate impression combined with a cast which has high dimensional stability $(1,8)$. As previously mentioned, several factors are effective in producing dimensional accuracy of impressions and resultant casts. One of these factors can be the contact time between cast and impression, although few studies have been done in this field. Therefore, due to a lack of information, the aim of this study was to investigate the effects of different contact times between stone and silicone impressions on the dimensional stability of the resultant casts. Before discussing about impression materials and techniques, it should be noted that the type of model used for making the impression in this research was made of stainless steel, and in addition, it was similar to the pattern used in Schleier's study (9). This kind of model has more dimensional stability compared to plaster or wax models.

Many different types of impression materials are available. In this study, the impression material Elite HD+ was chosen as the additional silicone gives it high dimensional stability (5), in addition, the Speedex impression material (a type of condensation silicone) was used due to its high consumption, ease of use, and its popularity among Iranian dentists (4). Among all the factors that have an effect on dimensional stability, the type of impression material is one of the most important factors $(11,12)$. In a comparative study conducted on 39 commercial impression materials by Craig, additional silicone had more stability compared to polysulfide, condensation silicone or polyether (13). Furthermore, Lin observed that polyether had the highest dimensional accuracy, while silicone, polysulfide, alginate and agar, were the next highest, respectively (14). In Faria's study, the accuracy of condensation silicone was similar to additional silicone using the double-mix technique (6). Nevertheless, Pereira et al. reported that among all the elastomeric impression materials, additional silicone had the highest accuracy and condensation silicone had the lowest accuracy (15). The results of the present study showed that the type of impression material did not have a statistically significant effect on the dimensional stability of the casts, which could be due to the high accuracy of both materials and technique used for the impressions. The difference between the results of this research compared to studies by Craig (13), Lin (14), and Pereira (15) may be due to differences in the type of impression material, impression technique, and method of study, between the researches. In different studies, the accuracy of the impression technique has been compared with each other. In studies by Stackhous et al. and Tjan et al. there was no difference in accuracy between the two stage impression technique with or without a spacer and the one stage technique $(16,17)$. Nili Ahmad Abadi et al. in their study, concluded that the two stage impression technique with a spacer has the greatest accuracy among the various methods (18). In addition, Mahshid et al. demonstrated that the two stage impression technique with a spacer is more accurate than the two stage impression technique without a spacer and the one stage impression technique (4). In the study of Nejati Danesh et al., the accuracy of three impression techniques with polyvinyl siloxane which included two stage technique with $1 \mathrm{~mm}$ space, two stage technique using a polyethylene spacer, and one stage technique, was investigated. The two stage technique with a $1 \mathrm{~mm}$ space was reported to be the most accurate technique in this study (10). Therefore, according to these studies, the present study also used the two stage impression technique. In this technique, heavy body silicone (putty) was used in the first stage and light body silicone was used in the second-stage (19).

The thickness of light body silicone is one of the factors that can have an effect on the dimensional stability of the final cast. For this reason, many studies have been done on this subject. For example, Nissan's study showed that it is appropriate to make accurate casts from light body silicone at thicknesses of 1 and $2 \mathrm{~mm}$. However, a 3 $\mathrm{mm}$ layer does not produce the same level of accuracy (20). Also, in the study of Eames et al. in which condensation silicone was used to make the impression, the effect of light body silicone thicknesses; $2 \mathrm{~mm}, 4 \mathrm{~mm}$, and $6 \mathrm{~mm}$,was investigated on the accuracy of the casts, and it was found that the $2 \mathrm{~mm}$ layer had the highest dimensional accuracy (21). Souri et al. in their research, found that the light body silicone thicknesses of $0,0.5$, $1,1.5$ and $2 \mathrm{~mm}$ did not have any statistically significant effect on the accuracy of the impressions (22). Inasmuch as in all these studies, a light body material $2 \mathrm{~mm}$ or less produced casts with the highest dimensional accuracy. In order to control the thickness of the wash material in the present study, corresponding to Faria's research (6), a $1 \mathrm{~mm}$ space (with stainless steel copings) was created for the wash material.

The results of this study showed that the effect of contact time on the dimensional stability of the cast at some of the distances was significant. The casts which were separated from the impressions after one hour, had at least dimensional changes, and with increased contact time between the stone and impression material, the dimensional stability of the cast decreased. Unfortunately, few studies have been done in this field and there is a lack of adequate scientific evidence to prove this issue. Therefore, we need to discuss this issue with caution, and further studies are needed in this regard. The only similar study was done by Marquezan et al. who investigated the effect of contact time (1 and 12 hours) between stone and alginate impression material, and it was found that increasing the contact time did not have any effect on the dimensional stability of the casts (8). Concerning the reasons for the difference in results between the latter and the present study can be attributed to the differences in the type of impression material 
used and the contact time between the stone and the impression (which were lower than the times tested in our study). In another related study by Michalakis et al. the effect of factors such as, type of stone, time and conditions of stone sample preservation, was investigated on their linear dimensional changes, and it was shown that all of these factors had a significant effect on the dimensional stability of the samples (23). In this study, the greatest expansion was recorded in the control group between 72 and 96 hours and for the tested group this occurred in the first 24 hours (23). The next highest results were for all of the samples in both groups that had been contracting for 2 weeks, and subsequently differences in measurements were not recorded between the second and third weeks (23).

The data of this study showed that a temperature of $40^{\circ} \mathrm{C}$ in combination with humidity less than $20 \%$ can lead to a significant contraction in the stone samples. This phenomenon can be explained due to the chemical nature of calcium sulphate. The chemical reaction between calcium sulphate hemihydrate (plaster powder) and water produces calcium sulphate dihydrate (dentistry plaster), which is an exothermic process. The preservation of the samples in an environment with increased temperature and decreased humidity, results in the dehydration of the samples and conversion of calcium sulphate dihydrate into calcium sulphate hemihydrate. This conversion is accompanied by a contraction in the sample which was first observed after 48 hours. The preservation of samples for longer periods in an environment with increased temperature and decreased humidity can cause further contraction of the samples. It should also be noted that contraction of the final casts is unsuitable because creating a smaller die, rather than prepared teeth, leads to unacceptable castings that will not sit on the abutments, unless this difference can be compensated for by applying a thicker layer of die spacer in the laboratory. Although the results of this compensating laboratory technique are unpredictable and are likely to be unsuitable (23). Regarding the mechanism of expansion, based on data obtained from electron microscope and x-ray refraction, Winkler et al. showed that the conversion of calcium sulphate hemihydrate into calcium sulphate dihydrate resulted from transformation of the crystals (from prismatic to needle shape hemihydrate), growth of these crystals, and collision with neighboring crystals causes expansion of the plaster (24). Investigating the average values of measurements in the present research showed that over time the casts expanded. The contact of cast with the impression was maintained at room temperature and no extra moisture or heat were applied in this present study, therefore, despite the results of the tested group in the study by Michalakis (23), no shrinkage took place in the casts, and similar to the control group in Michalakis's research (23), they expanded. The differences between some of the results of these two studies could be due to differences in their conditions and their performance. The results of this study suggest that over time, the amount of expansion increases (Table 3). As previously mentioned, the expansion of plaster is due to the transformation and growth of sulfate calcium crystals. With time and further growth of the crystals, the probability of collision with the next crystal increases and therefore, further expansion is expected. Furthermore, the present research showed that between the two types of impression materials used in this study, regardless of the contact time, there was no further advantage and the dimensional stability of both materials was acceptable. In evaluating the type of impression material and contact time, simultaneously, the results showed that the interaction of these two factors did not have any effect on the dimensional stability of the casts; this means that among the different groups from the point of dimensional stability, there was no significant superiority. The results of this study showed that the different contact times ( 1 hour, 24 hours, 48 hours and 1 week) between impression of the material and the stone had an effect on the dimensional stability of the casts, whereas, the type of impression materials (Speedex and Elite HD+) had no effect. Finally, the least dimensional changes were seen in the casts which were separated from the impression material after 1 hour.

\section{Acknowledgements}

The work described in this paper has been reterived from Dr. Zahra Dehbani's thesis. The authers would like to thank Dr. Javad Faradmal for useful statistical consultations.

\section{References}

1. Shillingburg HT, Hobo S, Whitsett LD, Jacobi R, Brackett SE. Fun damentals of fixed prosthodontics. 3th ed. The University of Michigan: Quintessence Pub Co;1997. pp. 281-9.

2. Petrie CS, Walker MP, O'Mahony A M, Spencer P. Dimensional accuracy and surface detail reproduction of two hydrophilic vinyl polysiloxane impression materials tested under dry, moist, and wet conditions. J Prosthet Dent. 2003;90(4):365-72.

3. Lee IK, DeLong R, Pintado MR, Malik R. Evaluation of factors affecting the accuracy of impressions using quantitative surface analysis. Oper Dent. 1995;20(6):246-52.

4. Mahshid M, Sabouri A, Kolahchi N, Valaei N. [Evaluation of dimensional accuracy of master models as a function of impression technique material with Speedex]. J Dent Sch Shahid Beheshti Univ Med Sci. 2004;22(2):320-31.

5. Thongthammachat S, Moore BK, Barco MT, 2nd, Hovijitra S, Brown DT, Andres CJ. Dimensional accuracy of dental casts: influence of tray material, impression material, and time.JProsthodont. 2002;11(2):98-108.

6. Faria AC, Rodrigues RC, Macedo AP, Mattos Mda G, Ribeiro RF. Accuracy of stone casts obtained by different impression materials. Braz Oral Res. 2008;22(4):293-8.

7. Ali KS, Shenoy VK, Rodrigues SJ. Comparative evaluation of dimensional accuracy of casts made by repeated pouring of addition siliconeimpressions using 1) Two-step putty/light-body technique using stock tray and 2) One-step simultaneousdual viscosity technique using custom tray: An in vitro study. J Nepal Dent Assoc . 2010;11(1):32-9.

8. Marquezan M, Jurach EM, Guimaraes VD, Valentim RG, Nojima 
LI, Nojima Mda C. Does the contact time of alginate with plaster cast influence its properties? Braz Oral Res. 2012;26(3):197201.

9. Schleier PE, Gardner FM, Nelson SK, Pashley DH. The effect of storage time on the accuracy and dimensional stability of reversible hydrocolloid impression material. J Prosthet Dent. 2001;86(3):244-50.

10. Nejati Danesh F, Koupaei H, Monirifard R, Savabi A. [Dimesional accuracy of three impression technique with putty-wash poly vinyl siloxane]. J Dent Sch Shahid Beheshti Univ Med Sci. 2008;26(4):412-9.

11. Chee WW, Donovan TE. Polyvinyl siloxane impression materials: a review of properties and techniques. $J$ Prosthet Dent. 1992;68(5):728-32.

12. Fano V, Gennari PU, Ortalli I. Dimensional stability of siliconebased impression materials. Dent Mater.1992;8(2):105-9.

13. Craig RG, Urquiola NJ, Liu CC. Comparison of commercial elastomeric impression materials. Oper Dent.1990;15(3):94-104.

14. Lin CC, Ziebert GJ, Donegan SJ, Dhuru VB. Accuracy of impression materials for complete-arch fixed partial dentures.J Prosthet Dent.1988;59(3):288-91.

15. Pereira JR, Murata KY, Valle AL, Ghizoni JS, Shiratori FK. Linear dimensional changes in plaster die models using different elastomeric materials. Braz Oral Res. 2010;24(3):336-41.

16. Stackhouse JA, Jr. The accuracy of stone dies made from rubber impression materials. J Prosthet Dent.1970;24(4):377-86.
17. Tjan AHL, Whang SB, Tjan AH. Clinically oriented assessment of the accuracy of three putty-wash silicone technique. J Am Dent Assoc. 1984;108(6):973-5.

18. Nili Ahmad Abadi M, Aghamiri N. [The effect of second wash in one stage and two stages impression technique on dimensional accuracy of plaster model]. J Dent Shiraz Univ Med Sci 2008;26(4):32-40.

19. Sakaguchi S, Benham H, Cope AP, Thomas R. T-cell receptor signaling and the pathogenesis of autoimmune arthritis: insights from mouse and man. Immunol Cell Biol. 2012;90(3):277-87.

20. Nissan J, Laufer BZ, Brosh T, Assif D. Accuracy of three polyvinyl siloxane putty-wash impression techniques. J Prosthet Dent. 2000;83(2):161-5.

21. Eames WB, Sieweke JC, Wallace SW, Rogers LB. Elastomeric im pression materials: effect of bulk on accuracy. J Prosthet Dent. 1979;41(3):304-7.

22. Souri H. [In vitro evaluation of the effect of space value for light body on accuracy of resultant casts from two stage impression technique]. Iran: Hamadan University of Medical Science; 2009.

23. Michalakis KX, Asar NV, Kapsampeli V, Magkavali-Trikka P, Pissiotis AL, Hirayama H. Delayed linear dimensional changes of five high strength gypsum products used for the fabrication of definitive casts. J Prosthet Dent. 2012;108(3):189-95.

24. Winkler MM, Monaghan P, Gilbert JL, Lautenschlager EP. Comparison of four techniques for monitoring the setting kinetics of gypsum. J Prosthet Dent. 1998;79(5):532-6. 